\title{
C-RANBBU 集中度模型及规划建设分析
}

张健

中国通信建设集团设计院有限公司第四分公司，河南 郑州 450052

[摘要]今年 6 月 6 日, 工信部 6 日正式向中国电信 (3.5G)、中国移动 (2.6G/4.8G)、中国联通 (3.6G)、中国广电 (700M/4.9G) 发放 $5 \mathrm{G}$ 商用牌照。5G 正式进行建设快车道。各大运营商纷纷启动 $5 \mathrm{G}$ 网络规模化建设。由于 $5 \mathrm{G}$ 手机等终端应用不成熟，价 格高, 商用前景不明确。而且, $5 \mathrm{G}$ 初期建设成本较高, 各运营商投资压力大, 同时基站建设受铁塔基站租货费用逐年上升影 响, 运营维护压力大。因此, $5 \mathrm{G}$ 建设初期, 需要通过 BBU 集中部署等方式, 减少分布式站址建设, 缩减建设投资, 保持良性 发展。

[关键词] C-RAN; BBU 集中度; 无线网络; 传输网络

DOI：10.33142/aem.v1i1.812 中图分类号: TN929.5

文献标识码：A

\section{The Concentration Model of C-RANA and the Analysis of the Planning and Construction ZHANG Jian}

China Communications Construction Group Design Institute Co., Ltd. Fourth Branch, Henan Zhengzhou, 450052 China

\begin{abstract}
June 6 this year, the Ministry of Industry and Information Technology officially issued 5G commercial licences to China Telecom (3.5G), China Mobile (2.6G/4.8G), China Unicom (3.6G) and China Radio and Television (700M/4.9G). 5G officially carried out the construction of fast lane. The major operators have launched a large-scale construction of 5G network. Due to the immature application of $5 \mathrm{G}$ mobile phone and other terminal applications, the price is high, and the commercial prospect is not clear. Moreover, the initial construction cost of $5 \mathrm{G}$ is high, and the investment pressure of each operator is high. at the same time, the construction of base station is affected by the rising rental cost of tower base station year by year, and the pressure of operation and maintenance is great. Therefore, $5 \mathrm{G}$ construction In the early days, it is necessary to reduce the construction of the distributed station site, reduce the construction investment and maintain the benign development through centralized deployment of the BBU and the like.
\end{abstract}

Keywords: C-RAN; BBU concentration; Wireless network; Transmission network

\section{C-RAN 对无线网的影响分析}

C-RAN 建设对现有无线网的主要影响应从成本花费、运营维护、网络演进等角度进行影响分析。

1.1 降低花费, 实现低成本建设需求

C-RAN 采用 BBU 集中式放置, 可节约大量租借或购买站址资源的成本。

同时, 通过减少机房及配套数量, 达到控制运营和维护开销的目的。

1. 2 易于协作

C-RAN BBU 集中式方案, 为站间协同提供了理想时延, 易于实现 CA, CoMP, super Ce11, 3D-MIM0 等功能。C-RAN 集中部署有利于引入协作化技术 CoMP (协同多点传输), 提升小区边缘速率。

低重叠覆盖区：小区边缘上行速率提升 8 15\%，小区边缘下行速率提升 $8 \sim 9 \%$ 。

高重叠覆盖区: 小区边缘上行速率提升 24４4\%，小区边缘下行速率提升 10～9\%。

\section{3 节能环保}

C-RAN BBU 集中式方式, 可减少大量的空调设施, 从而有效降低能耗。

基于负载的自适应资源分配, 动态调度资源, 提高资源利用率。

\section{4 易于无线网络演进}

未来无线网向云化、虚拟化方向发展，BU 将以逻辑形式集中， C-RAN 部署更易于向未来无线网络演进。

同时, C-RAN 符合 $5 \mathrm{G}$ 目标网架构, 有助于改善无线性能、提高频谱资源利用率, 较传统组网模式可显著降低建网 投资以及后续运维成本，同时在重大自然灾害中可以提高网络的生存能力。

\section{C-RAN 对传输网的影响分析}

C-RAN BBU 集中部署, 对于传输网的影响, 最典型就是减少了基站接入传输设备的放置数量, 从而节省基站机房空 
间，节约能源，节省建设成本。

但同时 C-RAN BBU 集中部署对传输网络建设也带来了巨大挑战。

首先, BBU 集中化部署, 必然对所在汇聚机房或者自有的基站机房等局房的空间和动力提出更高, BBU 高度集中, 对机房空间和电源配套要求高。

其次, $5 \mathrm{G}$ 网络的 CPRI 接口速率将明显高于 $4 \mathrm{G}$ 网络, 从几个 $\mathrm{G}$ 到数十个 $\mathrm{G}, 5 \mathrm{G}$ 前传压力较大, 一般采用光纤直驱 和波分两种可行的传输方式。无论采用何种方式, 都必然消耗大量的传输资源。同时, 前传 AAU 数量众多, 对 $5 \mathrm{G}$ 前传 光缆资源消耗巨大。

最后, 由于 C-RAN BBU 集中部署, 5G AAU 拉远放置, 使用光纤直驱, 除了无法实现端到端监控, 缺乏端到端监控 手段，必将导致运营维护风险加大。

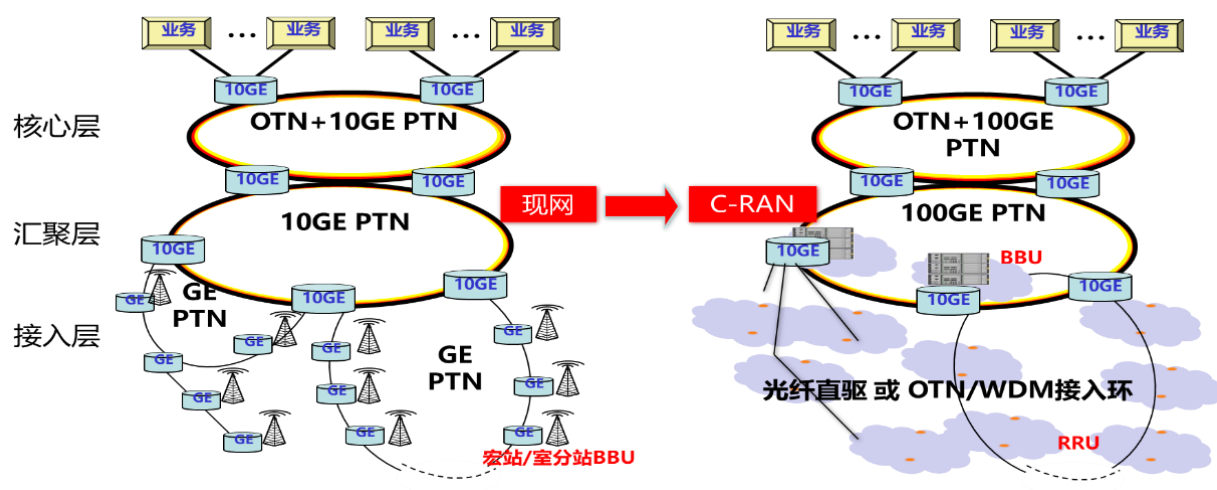

图 1 C-RAN 部署前后对传输网的影响分析示意图

\section{C-RAN BBU 集中度模型分析}

结合上述 C-RAN 机房部署对无线网络和传输网络的影响分析, 对 BBU 集中度按照高、低配置阐述 BBU 集中度模型 分析。

3. 1 BBU 典型配置

(1) $\mathrm{BBU}$ 高度: $2 \mathrm{U}-5 \mathrm{U}$

(2) 功耗: 1000-1500W

(3) 一个 $\mathrm{BBU}$ 支持 6-12 个 $\mathrm{RRU}$
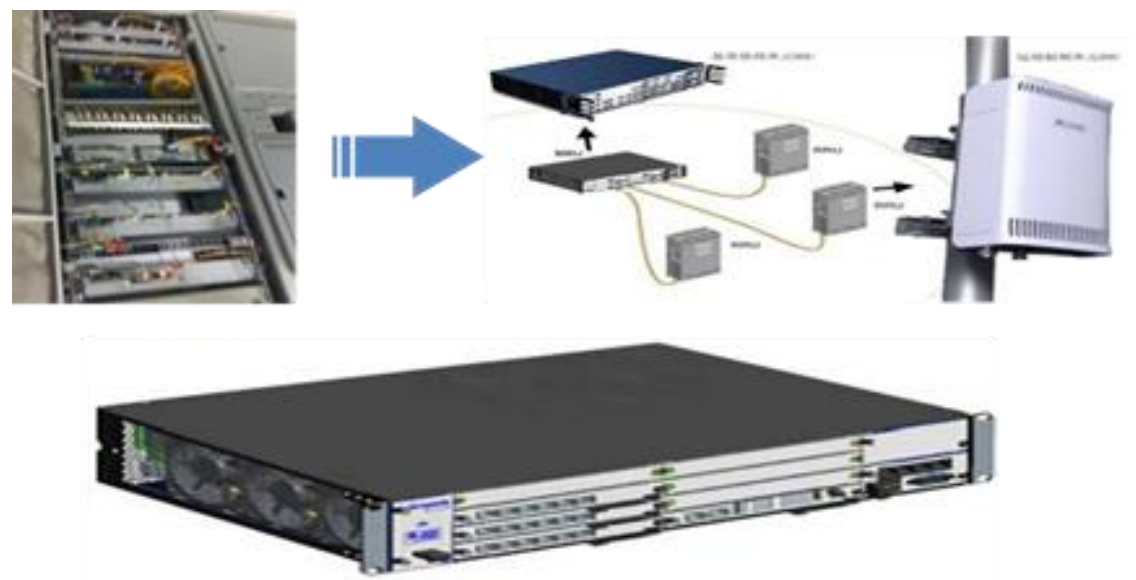

图 $2 \mathrm{BBU}$ 集中式部署安装及至 RRU 连接方式示意图

\section{3. $2 \mathrm{BBU}$ 集中度分析}

按照工信部《电信网络运行监督管理办法》中事故的定义:

“移动电话通信中断影响超过 10 万户，且持续超过 $1 \mathrm{~h}$ ” 为重大事故;

“移动电话通信中断影响超过 3 万户，且持续超过 $20 \mathrm{~min}$ ” 为较大事故; 
“移动电话通信中断影响超过 1 万户”属一般事故。

为确保不超过工信部定义的一般故障, 单 C-RAN 区域覆盖用户数不得超过 1 万户, 则平均覆盖面积为移动用户数 除以拟覆盖区域面积, 得出单平方公里用户数, 按照不超过 1 万户测算, 在仅考虑 $5 \mathrm{G}$ 基站集中部署的情况下, 计算单 平方公里范围内管辖的 $5 G$ 宏站均值数据，即为该区域 C-RAN BBU 集中度合理值。

基于上述分析, 结合不同地市城区的用户密度, 建议平均每个 C-RAN 区域覆盖不得超过 1 万户的区域面积, 同时 考虑在每个 C-RAN 区域内堆叠的物理站址数, 具体到每个 C-RAN 机房应当根据该机房的剩余可使用面积以及剩余可使 用电源容量确定物理站的堆叠数量。

\section{3 C-RAN 机房 BBU 高集中度分析-高配}

(1) 配置模型: BBU 集中度为 10 个单模 $5 G$ 站;

(2) 光纤需求: 光纤直驱方式需 30 芯，无源波分方式需 10 芯;

（3）备电时间: 为 C-RAN 单独配置蓄电池和开关电源, 备电时间 4 个 $h$;

(4) 装机空间: 新增传输机架、 $5 G$ 无线机架、ODF 架、空调;

(5) 机房使用面积: 剩余可装机位置不低于 9.5 个, 使用面积需求不低于 $9.3 \mathrm{~m}^{2}$;

(6) 外市电引入: 市电容量需求不低于 $27.5 \mathrm{~kW} 。$

\section{4 C-RAN 机房 BBU 高集中度分析-低配}

(1) 配置模型: BBU 集中度为 5 个单模 $5 \mathrm{G}$ 站;

(2) 光纤需求: 光纤直驱方式需 15 芯，无源波分方式需 5 芯;

(3) 装机空间: 利旧原机房的开关电源、蓄电池、 $O D F$ 架、传输机架; 新增 $5 \mathrm{G}$ 无线机架、空调;

(4) 机房使用面积: 剩余可装机位置不低 2 个, 使用面积需求不低于 $2 \mathrm{~m}^{2}$;

(5) 外市电引入: 市电容量需求不低于 $8.5 \mathrm{~kW}$ 。

\section{C-RAN 规划应用前景}

综上所述, C-RAN 的部署利弊参半, 既有带来的好处, 也将面临的诸多挑战, 参照目前各运营商对 5G C-RAN 的部 署研究。建议面向 $5 \mathrm{G}$ 竞争的需求, 以运营商现有的汇聚机房、自有基站机房等局房资源为基础, 适度开展 $\mathrm{BBU}$ 的集中 部署, 实现快速建网, 保持竞争优势。目前 $5 \mathrm{G}$ 网络建设, 各运营商均处于同一起跑线, 面对市场竞争, 为保持网络竞 争优势, 需要快速建设网。采用 C-RAN 模式, 点少面光, 快速实现 $5 \mathrm{G}$ 网络连续覆盖, 逐步完善前传网络, 形成网络竞 争优势。

\section{[参考文献]}

[1]罗新军.徐舜尧. 基于 TD-LTE 的 C-RAN 传输解决方案 [J]. 通信电源技术, 2019,05(181) : 183.

[2]罗新军. 基于 TD-LTE 的 C-RAN 技术解决方案 [J]。电信技术, 2017, 12 (62) : 64 .

[3] 雷秋燕, 张治中, 程方, 胡昊南. 基于 C-RAN 的 5G 无线接入网架构 $[\mathrm{J}]$. 电信科学, 2015,01 (112): 121.

[4]崔鸣,黄坤,牛春, 汤旭辉. C-RAN 传输解决方案浅析 [J]. 信息通信, 2019,05 (213) : 216.

作者简介: 张健（1967-）男，学历：硕士研究生，专业方向：企业经营管理. 